\title{
Mobile Phone Surveys: The Slovenian Case Study
}

\author{
Vasja Vehovar ${ }^{1}$, Eva Belak ${ }^{2}$, Zenel Batagelj ${ }^{3}$, and Sanja Čikić ${ }^{4}$
}

\begin{abstract}
In 2004, the number of mobile phone subscriptions in Slovenia reached the total number of inhabitants. Consequently, the fixed telephone coverage has started to decline; almost $10 \%$ of households are now available only over the mobile phone. With this, Slovenia positions itself as a typical EU country and can serve as a case study for issues related to mobile phone interview surveys.

The paper addresses the general context of mobile phone usage and the calculations of mobile phone coverage rates. It also discusses the noncoverage problems related to mobile and mobile-only households. It is shown, that even with a relatively small non-coverage the corresponding estimates can be considerably biased, as in the case of the unemployment rate in the Slovenian Labour Force Survey.

There are severe methodological problems with mobile phone interview surveys. In particular, a pilot mobile phone survey confirmed the disadvantages of costs, frames and response rates, at least when compared to fixed telephone surveys. In addition, the response rates are dramatically lower for less intensive mobile phone users.

The comparisons of respondents in mobile phone surveys with the corresponding sub-samples in Labour Force Surveys and in fixed telephone surveys revealed some specific discrepancies in the socio-demographic structure. Due to non-coverage, the respondents in the mobile phone survey tend to be younger, higher educated, from larger households and are represented by a larger share of males. The non-response mechanism can additionally reinforce these effects (e.g gender), however it can also cancel them (e.g. age, household size). Special complexity arises from the diverse effects of the non-response components (refusal vs. non-contact).

According to their attitudes towards mobile phone use, mobile phone users compose three distinct segments (intensive pragmatic and emotional users, less intensive users) that may behave differentially also during the mobile phone survey process.
\end{abstract}

\footnotetext{
${ }^{1}$ Faculy of Social Sciences, University of Ljubljana, Slovenia; vasja.vehovar@guest.arnes.si

${ }^{2}$ Statistical Office of the Republic of Slovenia

${ }^{3}$ CATI, Slovenia

${ }^{4}$ Faculy of Social Sciences, University of Ljubljana, Slovenia
} 


\section{Introduction}

The growing mobile phone penetration in developed countries is often accompanied with decreasing trends in fixed telephone coverage. An increasing number of households are giving up their fixed telephones, as they start to rely merely on their mobile phones (mobile-only households). The problem is most severe in Finland, where the share of mobile-only households has already approached almost 40\% (Kuusela and Simpanen, 2002). However, in the majority of EU countries the issue has not proven so severe, at least in 2003. The mobileonly households typically present around $10 \%$ of all households (Vehovar et al., 2004a). On the other hand, the share of the active population with a personal mobile phone device approached or exceeded $75 \%$ in almost all EU-15 countries, as well as in the majority of EU-10 new countries (RIS, 2004). As the trends roughly follow the path of Finland, we can expect that the developed countries will soon face a serious problem of fixed telephone non-coverage (Vehovar et al., 2004b). Consequently, mobile phone surveys will become a necessary alternative.

In this paper we address the general problems of mobile phone interview surveys and the corresponding applications in the Slovenian environment. For this purpose Slovenia acts as a typical EU country, with mobile phone penetration slightly above the EU-15 average and with an increasing share of mobile-only households.

In Section 2 we discuss the general issues of mobile phone surveys, while in Section 3, the Slovenian case study is presented. There, we discuss the calculations of various mobile phone penetration rates. Next, we compare the respondents in a pilot mobile phone survey with those in face-to-face (LFS Labour Force Survey) and fixed telephone surveys (RIS Research on the Internet in Slovenia). In the conclusion, we summarise the findings and discuss the areas of future research (Section 4).

\section{Mobile phone surveys}

The data from mobile phone operators show that in the beginning of 2003 (Mobile Communications, 2003) the median subscription mobile phone penetration rate for the EU-15 countries equalled 83\%. This measure compares the number of active mobile phone subscriptions - as reported by mobile phone operators - and the size of the total population. On the extreme side, some countries already surpassed the $100 \%$ subscription mobile phone penetration rate by the end of 2003 , i.e. there were more mobile phone subscriptions than inhabitants (e.g. Island). In 2004 , Slovenia is also expected to surpass this $100 \%$ penetration rate (RIS, 2004). 
Different results are obtained for the personal mobile phone penetration rate, which expresses the share of respondents with a personal mobile phone device within the target population (e.g. active or total population). Here, the estimate for median personal mobile phone penetration rate amongst the active population (15+) in the EU-15 countries is 79\% in the beginning of 2003 (SIBIS, 2003). Obviously, we have to be very distinctive in separating these two mobile phone penetration rates (personal vs. subscription).

Finland is undoubtedly the leader in mobile phone penetration. The subscription mobile phone penetration reached 60\% already in 1998 and has now stabilised at around 95\%. The share of households with a mobile phone is also approaching 95\%, while fixed telephone coverage is declining towards $60 \%$ with almost $40 \%$ of mobile only households (Kuusela and Simpanen, 2002). Other Scandinavian and some Baltic countries are also following this pattern. However, the majority of EU-15 countries and the new member states position themselves within the earlier stages of this process (Vehovar et al., 2004a).

Here we should add that besides the increasing mobile phone penetration, the social context of mobile phone usage is also important (Katz, 2003). The mobile phone is a very private device, thus its social role considerably differs from fixed telephones. Due to its personalised usage, we may expect different patterns of handling this device, as well as different perception and attitudes (Rheingold, 2002). The variety of social and usability contexts of mobile phone use may also have certain impacts on the way users accept its role as a survey device. The potential impacts are discussed within the context of mobile phone users segmentation in Section 3.3.3., while a broader discussion can be found in Vehovar et al. (2004a).

The key advantage of introducing a mobile phone survey is the improved coverage of fixed telephone surveys, because we can reach the segment of mobileonly households. In general, coverage is an extremely important issue in the design of surveys. It has been over fifty years since the Literary Digest mail survey predicted a landslide victory for Landon over Roosvelt in the 1936 U.S. presidential election and non-coverage of the sampling frame was cited as the key reason for the erroneous prediction. Coverage issues were problematic also with the introduction of fixed telephone surveys, where a minimum requirement of $80 \%$ for fixed telephone coverage was suggested (Groves et al., 2001). The rise of the Internet surveys was also accompanied with a high concern for the non-coverage problem (Vehovar et al., 2002).

On the other hand, mobile phone interview surveys face many methodological problems, particularly those related to costs, frames and response rates (Vehovar et al., 2004a):

- Costs. Typically, per minute charges are a few times higher compared to fixed telephones. In some countries (e.g. US) even the person being called is charged. 
- Frame. In many countries prepaid mobile phone users dominate; for them there is no personal identification at all. Among the subscribers unlisted users are also numerous, with business numbers mixed with personal ones. The potential sampling frames suffer also from multiple operators, users with more devices (or SIM cards), and particularly from the lost link between the mobile phone number and the geographical location.

- Response rates. In Finland, Kuusela and Simpanen (2002) report that increased contact rates compensated a slight increase in the refusal rate. However, the experience from Slovenia (section 3.3) points to a much lower response rate for mobile phone surveys.

Other aspects can also be problematic with mobile phone surveys, such as legal problems, technological issues and mode effect.

The position of the mobile phone surveys is thus determined not only by the expanded usage and penetration rates but also with frames, technology, cultural issues, response behaviour, costs and legal restrictions.

\section{The Slovenian case study}

By the end of 2003, the subscription mobile phone penetration rate in Slovenia was $97 \%$ according to EMC, Mobile Communication International (2003), while at the end of 2002 it was $85 \%$. On the other hand, according to the SIBIS Survey (2003), the personal mobile phone penetration rate in Slovenia at the beginning of 2003 was $82 \%$ amongst the active population. Before we investigate this discrepancy further, we would like to present also other data sources.

Table 1: Households (\%) in Slovenia according to fixed and mobile phones (Source: Labour Force Survey 2003, $2^{\text {nd }}$ Quarter, $1^{\text {st }}$ wave, $n=1534$, Statistical Office of the Republic of Slovenia).

\begin{tabular}{|l|c|r|r|r|}
\hline \multicolumn{2}{|c|}{} & \multicolumn{2}{|c|}{ Mobile phone } & \multirow{2}{*}{ Total } \\
\cline { 3 - 4 } \multicolumn{2}{|c|}{} & \multicolumn{1}{c|}{ Yes } & \multicolumn{1}{c|}{ No } & \\
\hline \multirow{2}{*}{$\begin{array}{l}\text { Fixed } \\
\text { Phone }\end{array}$} & Yes & 75.0 & 16.0 & 91.0 \\
\cline { 2 - 5 } & No & 7.0 & 2.0 & 9.0 \\
\hline \multicolumn{1}{|c|}{ Total } & & 82.0 & 18.0 & 100.0 \\
\hline
\end{tabular}

The LFS (Labour Force Survey) data confirms the high mobile phone penetration in 2003, as $82 \%$ of Slovenian households have at least one person with 
a mobile phone. In addition, we can observe there are $7 \%$ of mobile-only households in Slovenia.

Somewhat different results can be obtained from regular RIS (Research on the Internet in Slovenia) telephone surveys $(n=1,000)$. According to these standardised fixed telephone surveys, only 59\% of the target population (10-75 years) were using mobile phones in 2000, in 2001 this percentage has risen to already $70 \%$, while at the beginning of 2003 almost $85 \%$ of the respondents reported personal use of a mobile phone.

We can also note that with increased mobile phone penetration, the share of less intensive mobile phone users increases. In 2001 there were only 8\% of occasional mobile phone users (they do not use their mobile phone on a daily basis) among all of the respondents in the RIS telephone survey, while in the beginning of 2003 their share increased to $21 \%$.

\subsection{Mobile phones in the Slovenian Labour Force Survey}

Let us present a more detailed analysis of the Labour Force Survey (LFS) data, where the question regarding personal mobile phone device was posed to all respondents aged seven years or more.

Table 2: Persons (\%) in Slovenian households with respect to their availability on fixed and mobile phones in their household (Source: Labour Force Survey 2003, n=4,500,

Statistical Office of the Republic of Slovenia).

\begin{tabular}{|l|c|r|r|r|}
\hline \multicolumn{2}{|c|}{} & \multicolumn{2}{|c|}{ Mobile Phone } & \multirow{2}{*}{ Total } \\
\cline { 3 - 4 } \multicolumn{2}{|c|}{} & \multicolumn{1}{|c|}{ Yes } & \multicolumn{1}{c|}{ No } & \\
\hline \multirow{2}{*}{$\begin{array}{l}\text { Fixed } \\
\text { Phone }\end{array}$} & Yes & 79.1 & 11.9 & 91.0 \\
\cline { 2 - 5 } & No & 7.3 & 1.7 & 9.0 \\
\hline Total & & 88.4 & 13.6 & 100.0 \\
\hline
\end{tabular}

\subsubsection{Mobile phone penetration}

Similar to Table 1, Table 2 refers to the household level characteristics, however in this case we observe them on a personal level. $7.3 \%$ of persons live in mobileonly households (Table 2), while on the other hand, there are $7.0 \%$ of households with no fixed telephone where at least one person has a mobile phone (mobile-only households in Table 1). We come across much higher differences in the remaining three segments, so we need to be extremely precise when talking about mobile 
phone coverage, as it is easy to overlook the level of observation and/or the level of characteristics.

Now let's observe the same data on the level of personal mobile phone usage (Table 3). At this we discuss personal characteristics and not the household level availability.

Table 3: Persons (\%) according to fixed telephones in households and according to personal mobile phone use (Source: Labour Force Survey 2003, 2nd Quarter, 1st wave, $\mathrm{n}=4,500$, Statistical Office of the Republic of Slovenia).

\begin{tabular}{|l|c|r|r|r|}
\hline \multicolumn{2}{|c|}{} & \multicolumn{2}{|c|}{ Mobile Phone } & \multirow{2}{*}{ Total } \\
\cline { 3 - 4 } \multicolumn{2}{|c|}{} & \multicolumn{1}{|c|}{ Yes } & \multicolumn{1}{c|}{ No } & \\
\hline \multirow{2}{*}{$\begin{array}{l}\text { Fixed } \\
\text { Phone }\end{array}$} & Yes & 57.1 & 33.9 & 91.0 \\
\cline { 2 - 5 } & No & 5.5 & 3.5 & 9.0 \\
\hline Total & & 62.6 & 37.4 & 100.0 \\
\hline
\end{tabular}

We now have three figures for personal mobile phone coverage:

- $82.0 \%$ of households have at least one person with a mobile phone,

- $88.4 \%$ of persons live in households where at least one person has a mobile phone,

- $62.6 \%$ of persons in the total population own a personal mobile phone.

Table 4: Personal mobile phone use in different age segments (Source: Labour Force Survey 2003, 2nd Quarter, 1st wave, n=1,534, Statistical Office of the Republic of Slovenia).

\begin{tabular}{|c|c|}
\hline Age group & Mobile phone $\%$ \\
\hline $18+$ & 61.5 \\
\hline $15+$ & 62.3 \\
\hline $0-75$ & 65.6 \\
\hline $7+$ & 65.8 \\
\hline $7-75$ & 70.1 \\
\hline $10-75$ & 72.4 \\
\hline Total & $\mathbf{6 2 . 6}$ \\
\hline
\end{tabular}

Further differences can arise due to the age restrictions within the target segment. At this point we should recall that we excluded the users under the age of seven. However, we estimated that there are less of 5,000 of them in this category, 
as we extrapolated the penetration rate for 5-6 years to around 7\%. Mobile phone penetration rates (Table 4 ) thus vary from $72.4 \%$ in the $10-75$ year age group down to $61.5 \%$ amongst the entire adult population $(18+)$.

The above personal mobile phone penetration rate is relatively low compared to the subscriber mobile phone penetration discussed in the introduction of Section 3. According to the EMC database (by the end of 2003), which relies on the reports from all three Slovenian mobile phone operators (Mobitel, SimobilVodfone, WesternWireless), there should be around 1.94 million active mobile phone subscriptions in Slovenia (i.e. subscription mobile phone penetration rate of 97\%). A corresponding figure for the end of 2002 gives 1.7 million subscriptions (85\%). We can parallel these figures with the Labour Force Survey data for the first quarter of 2003 , where we have the estimate of 1.25 million persons (i.e. personal mobile phone penetration rate of $62.6 \%$ in a 2 million population) that report mobile phone usage.

The differences occur due to the methodological approaches of these two measures. In addition to a certain time lag, the following two factors need to be exposed:

- Some persons have multiple mobile phones (or SIM cards). The survey estimates that persons with multiple mobile phones vary within the range of $12 \%$ (fixed telephone surveys) to $16 \%$ (mobile phone surveys) of all mobile phone users. In addition, the number of users with more than two mobile phones or SIM cards is approximately $3 \%$.

- The definition of an active mobile phone subscription according to mobile operators (EMC database) is very broad and relatively ambiguous, especially for prepaid subscriptions. A typical example would be a prepaid mobile phone number, which is no longer used. However, the operators would typically threat it as an active number for an additional 6 or 9 months.

Of course, certain other methodological specifics with the EMC database and LFS data may also exist. This is particularly relevant, as another face-to-face survey from the beginning of 2003 gave the estimate of $85 \%$ for personal mobile phone penetration rate amidst the active population (SIBIS 2003).

\subsubsection{Socio-demographic characteristics}

Let us observe some additional characteristics of the four segments from Table 3. As can be observed from Table 5, there is a significantly greater percentage of females (38\%) in fixed-telephone-only households than males (29.6\%). In addition, the share of fixed-only households increases with age, while the corresponding share of mobile households simultaneously decreases. The opposite 
is true for education and household size, where the share of fixed-only households decreases with higher education, as well as with larger households. With some simplifications, we can attribute all these specifics to the older-single-woman effect, which is very strong in Slovenia. Obviously, this is a segment with relatively low mobile phone penetration.

Table 5: Persons according to the fixed telephone household and the personal usage of the mobile phone (Source: Labour Force Survey 2003, $2^{\text {nd }}$ Quarter, $1^{\text {st }}$ wave, $n=4,500$,

Statistical Office of the Republic of Slovenia).

\begin{tabular}{|c|c|c|c|c|c|}
\hline & \multicolumn{5}{|c|}{ Mobile only \% Fixed \& Mobile\% Fixed only \% No phone \% Total \% } \\
\hline \multicolumn{6}{|l|}{ Gender } \\
\hline Male & 5.7 & 61.5 & 29.6 & 3.2 & 100.00 \\
\hline Female & 5.4 & 52.9 & 38.0 & 3.8 & 100.00 \\
\hline \multicolumn{6}{|l|}{ Age } \\
\hline $0-14$ & 3.0 & 25.6 & 64.0 & 7.3 & 100 \\
\hline $15-24$ & 6.7 & 85.4 & 5.7 & 2.2 & 100 \\
\hline $25-34$ & 7.1 & 84.2 & 6.8 & 1.9 & 100 \\
\hline $35-44$ & 9.0 & 72.2 & 16.8 & 2.0 & 100 \\
\hline $45-59$ & 5.1 & 62.0 & 30.6 & 2.3 & 100 \\
\hline $60+$ & 3.3 & 24.3 & 67.4 & 5.0 & 100 \\
\hline \multicolumn{6}{|l|}{ Education } \\
\hline Children $(<15)$ & 3.0 & 25.6 & 64.0 & 7.3 & 100.0 \\
\hline Elementary & 5.2 & 40.1 & 49.2 & 5.5 & 100.0 \\
\hline Vocational & 7.8 & 61.3 & 28.5 & 2.4 & 100.0 \\
\hline Secondary & 6.1 & 76.5 & 16.0 & 1.4 & 100.0 \\
\hline $\begin{array}{l}\text { College, } \\
\text { University }\end{array}$ & 3.6 & 83.1 & 12.3 & 1.1 & 100.0 \\
\hline \multicolumn{6}{|l|}{ Household Size } \\
\hline 1 & 12.5 & 32.2 & 43.5 & 11.9 & 100.0 \\
\hline 2 & 8.2 & 43.9 & 45.0 & 3.0 & 100.0 \\
\hline 3 & 4.7 & 67.4 & 25.8 & 2.2 & 100.0 \\
\hline 4 & 3.6 & 65.6 & 28.5 & 2.4 & 100.0 \\
\hline $5+$ & 2.9 & 57.0 & 36.7 & 3.4 & 100.0 \\
\hline Total & 5.5 & 57.1 & 33.9 & 3.5 & 100.0 \\
\hline
\end{tabular}


To summarise, personal mobile phone coverage in Slovenia is around $70 \%$ (Table 4) and it is biased towards certain segments. Persons available for mobile phone surveys tend to be younger, higher educated, from larger households and with an increased share of males.

With respect to persons living in mobile-only households, we have similar socio-demographic characteristics for age (younger) and gender (a higher share of male), however, with the education picture the relation is not as clear, because the share of persons with college education is relatively small in this segment. On the other hand, we also have a relatively high share of single person households.

We can find a similar trend also in other countries. In Finland, for example, almost half of the single person households use only mobile phones (49.4\%), while the corresponding share among all households in below 30\% (Kuusela and Simpanen, 2002). As we observed in Slovenia, there is a much larger share $(12.5 \%)$ of mobile-only households, compared to $5.5 \%$ share in the total population (Table 5) amongst persons in single households.

There is also one country specific related to the segment of two-person singleparent households. They are very intensive mobile phone users and among them we found a surprisingly large share of mobile-only households.

\subsubsection{Potential bias}

The above variations of characteristics across different socio-demographic subgroups suggest that differences exist also in target variables. Let us illustrate this with an example. We start with a well-known expression, which can be applied also for mobile phone non-coverage (Biemer and Lyberg, 2003):

$$
\operatorname{Bias}(\bar{y})=W_{n} \times\left(\bar{Y}_{n}-\bar{Y}_{r}\right)
$$

where $W_{n}$ denotes the share of the non-observed target population (i.e. persons in mobile-only households) and averages denote the means in the observed and nonobserved population.

The results from the Labour Force Survey demonstrate that when omitting the mobile-only population, a bias of $0.3 \%$ occurs in the estimate of the unemployment rate. Instead of the actual estimate of $6.70 \%$ we now get the estimate of $6.38 \%$ from the remaining three segments. The following bias can be calculated also by using the above formulae:

$$
\operatorname{Bias}(\bar{y})=0.052 \times(0.122-0.0638)=0.00332
$$


Table 6: Unemployment rates in four segments of the population according to the type of telephone accessibility (Source: Labour Force Survey 2003, 2nd Quarter, 1st wave, $\mathrm{n}=1,534$, Statistical Office of the Republic of Slovenia).

\begin{tabular}{|c|r|r|}
\hline Segment & $\begin{array}{c}\text { Estimate of the } \\
\text { unemployment rate } \\
\boldsymbol{p} \%\end{array}$ & $\begin{array}{c}\text { Coefficient of } \\
\text { Variation of } \boldsymbol{p} \\
\mathbf{c v}(\boldsymbol{p}) \%\end{array}$ \\
\hline Mobile only & 12.2 & 28.3 \\
\hline $\begin{array}{c}\text { Mobile and } \\
\text { fixed }\end{array}$ & 5.9 & 10.4 \\
\hline Fixed only & 6.4 & 21.4 \\
\hline No phone & 24.1 & 24.5 \\
\hline Total & $\mathbf{6 . 7}$ & $\mathbf{8 . 7}$ \\
\hline
\end{tabular}

The value $W_{n}=0.052$ appears here for the first time, because it is the share of mobile-only persons amongst the active population (15+). This is a subset of the total population (Tables 1-3) and differs slightly from the corresponding share amongst the total population (5.5\% in Table 3$)$.

The above bias is not entirely negligible as it accounts for around 5\% of the value of the estimate. Such a high relative bias also surpasses the EU requirement for the estimate precision of national Labour Force Surveys, where the corresponding coefficient of variation is required to remain below 5\%. Obviously, even a small proportion of non-observed population could produce a considerable bias in the estimate. Of course, at this survey the differences between observed and non-observed populations were extremely large, reaching almost $100 \%$ (i.e. unemployment rate was $12.2 \%$ among the mobile only segment vs. $6.4 \%$, among the fixed only segment, Table 6).

One may also expect that the weighting of the sample without mobile-only persons may additionally improve the estimates. However, the actual weighting on the $94.8 \%$ of the sample by omitting the mobile-only persons $(5.2 \%)$ shows only negligible improvements, due to the fact that the standard weighting procedures at the Statistical Office is limited to post-stratification according to age and gender.

However, if we omit both segments that cannot be reached by fixed telephone, that is mobile-only and persons without any telephone, non-coverage amounts up to $8.7 \%$, while the corresponding bias increases to $0.6 \%$. In such an event we would underestimate the unemployment rate even more radically, obtaining $6.1 \%$ instead of $6.7 \%$.

On the other hand, if we observe only persons with mobile phones, the estimate is also slightly lower (6.4\%), as the segment with the lowest unemployment rate - i.e. persons with a mobile and fixed telephone - dominates the structure much stronger compared to the total sample. From the aspect of 
coverage, the mobile phone survey would thus underestimate the unemployment rate.

Of course, we can expect similar specifics also with other variables, although it is often true that with attitudes and opinions the differences are typically much smaller.

\subsection{Pilot mobile phone survey}

In September 2003 a pilot mobile phone survey was conducted within the RIS (Research on the Internet in Slovenia) project at the Faculty of Social Sciences, University of Ljubljana (RIS, 2004). The sampling frame consisted of two prefixes $(031,041)$ of the dominant mobile phone operator Mobitel (with a market share of $72 \%{ }^{5}$ ). Due to the significantly lower costs (i.e. 2 cents, compared to approx. 10 cents in GSM-GSM charges) the calls were made from the NMT to the GSM network.

\subsubsection{General characteristics}

The sample selection was a simple systematic selection within both prefixes (031, 041), each with a potential of a million six-digit numbers. The sampling interval of 3,636 was applied and this gave the initial sample size of $n=550$. The clustered selection (i.e. Mitofski-Waksberg) was not applied here, because of the high density of numbers. The likelihood of obtaining an active number was around $66 \%$.

The calling time was from 10 AM to 9 PM, Thursday-Sunday, September 12$14^{\text {th }}$. No restrictions were made according to the age of the respondents. With respect to the situation as to where the respondents were caught during the call, the interview was usually performed at home $(71 \%)$, but also in public places, during leisure activities $(18 \%)$ or at work $(10 \%)$.

According to the AAPOR standards (http://www.aapor.org/) we can summarise the figures in Table 7 into response rates, and obtain a response rate of $37.7 \%$ and a co-operation rate of $57.4 \%$. Proper comparisons with fixed telephone surveys are relatively complicated, however, the publicly well-known monthly telephone survey called Politbarometer of the same Faculty of Social Sciences, has a typical co-operation rate of $70 \%$ and a response rate of around $50 \%$. On the other hand, even the best commercial agencies with their key important fixed telephone surveys (e.g. National Readership Survey) do not achieve response and cooperation rates above the mobile phone survey.

\footnotetext{
${ }^{5}$ According to the information on the operator's official page: www.mobitel.si.
} 
Table 7: Final outcomes of the RIS mobile phone survey 2003 ( $n=103)$.

\begin{tabular}{|l|r|}
\hline Final response status in \% \\
\hline Interview & 26 \\
\hline Complete & 1 \\
\hline Partial & \\
\hline Eligible, non interview & 21 \\
\hline Refusal & 6 \\
\hline Respondent never available & 2 \\
\hline Miscellaneous (Respondent abroad, \\
incurring in roaming charges) & \\
\hline Unknown eligibility, non-interview & 2 \\
\hline Always busy & 2 \\
\hline No answer & 8 \\
\hline Answering machine & 1 \\
\hline Other (message from the company) & 32 \\
\hline Not eligible & $\mathbf{1 0 0}$ \\
\hline Non working number & \\
\hline Total & \\
\hline
\end{tabular}

With respect to the socio-demographic structure we can say that it roughly reflects the structure of the population. The only exception was the fact that there was a considerably larger share of students but fewer retired persons (10\% instead of $20 \%$ ) in the mobile phone sample. In all other aspects, we can see no statistically significant differences in the socio-demographic variables. Of course, we have to consider a relatively small sample size, as well as the sampling frame, which included only $72 \%$ of all mobile phone subscribers (i.e. from the mobile operator Mobitel). However, we do not expect that the users from the other two operators would be dramatically different.

Besides the socio-demographic differences, other specifics of the respondents from mobile phone surveys arise from mobile phone usage. The largest discrepancy relates to the intensity of mobile phone use. For a corresponding comparison, we need to compare the results of the mobile phone survey with the data from the general population survey.

We can observe that according to the fixed telephone survey (Table 8) two thirds $(64 \%)$ of the Slovenian general population (10-75 years) use the mobile phone on a daily basis. If we omit nonusers (16\%), the share of daily users among mobile phone users is even larger $(76 \%)$. On the other hand, in the pilot mobile phone survey (in 2003), all respondents were daily users. Such a radical 
discrepancy arises from various reasons. It is difficult to separate the effect of lower contact rates for less intensive mobile phone users from the differences in corresponding refusal rates, as well as from the differences in sampling frames and survey modes of these two surveys.

Table 8: Frequency of mobile phone usage (Source: RIS General Population Survey 2003, RIS Mobile Phone Survey 2003).

\begin{tabular}{|l|c|c|}
\hline & $\begin{array}{c}\text { RIS General } \\
\text { Population } \\
\text { Telephone Survey, } \\
\text { January 2003 } \\
\mathbf{n = 1 . 7 5 2}\end{array}$ & $\begin{array}{c}\text { RIS Mobile } \\
\text { Phone Survey, } \\
\text { September 2003 } \\
\text { n=103 }\end{array}$ \\
\hline Frequency of usage & $\%$ & $\%$ \\
\hline Daily & 64 & 100 \\
\hline A few times a week & 12 & - \\
\hline Once a week & 2 & - \\
\hline A few times a month & 3 & - \\
\hline Sometimes & 4 & $\mathbf{1 0 0}$ \\
\hline Never & 16 & $\mathbf{1 0 0}$ \\
\hline Total & \multicolumn{2}{|c|}{} \\
\hline
\end{tabular}

In addition, one third of the respondents in the mobile phone survey report over 10 calls daily, while amongst the general population of mobile phone users such users represent only $25 \%$.

\subsubsection{Non-coverage and non-response}

We already discussed the potential non-coverage of mobile phone surveys in the LFS data (Table 5). Due to the mobile phone coverage insufficiency, some segments can be underrepresented in the mobile phone survey, in particular woman, older and less educated persons, as well as persons in single person households.

However, the actual structure of respondents in the mobile phone survey also includes the effects of non-response. Here, we have no direct data on the nonresponse effect, so we infer about it indirectly. By comparing the structures of the samples (Table 9), we attribute the differences between the second and third column (LFS data) to non-coverage, while the differences among the last two columns are attributed to non-response. 
In some cases, such as gender, the non-response mechanism thus tends to reinforce the effect of non-coverage. On the other hand, non-response may act also in the opposite direction and can weaken or cancel the impact of non-coverage. As an illustration, the share of persons in single households and the share in the 15 19 age group are presented.

Table 9: Shares (\%) of some socio-demographic categories amidst the active population and mobile phone users in the LFS survey, and in the mobile phone survey (Source: LFS,

First quarter 2003; Mobile Phone Survey, RIS 2003).

\begin{tabular}{|l|r|r|r|}
\hline Segment & \multicolumn{1}{|c|}{$\begin{array}{c}\text { LFS survey } \\
\text { All respondents }\end{array}$} & $\begin{array}{c}\text { LFS survey } \\
\text { Mobile phone users }\end{array}$ & $\begin{array}{c}\text { RIS Mobile } \\
\text { Phone Survey }\end{array}$ \\
\hline Male & 48.5 & 52.0 & 53.4 \\
\hline Single households & 9.5 & 7.9 & 8.6 \\
\hline Age 15-19 & 7.7 & 10.4 & 9.1 \\
\hline
\end{tabular}

A much larger non-response effect can be found in certain specific segments. The LFS estimate for the share of mobile-only persons (8.5\%) among mobile phone users is much lower than the corresponding estimate from the mobile phone survey (18\%). A simple calculation shows that if the response rate among mobileonly persons is $100 \%$, the response rate among the non mobile-only users (i.e. persons with a mobile and a fixed telephone) need to be $48.5 \%$ to obtain the given ration of shares $(8.5 \%$ vs. $18 \%)$ of mobile-only persons in these two surveys. Such a high discrepancy seems somehow unlikely, thus the issue remains relatively unclear. However, it is reasonable to explain it as a considerable non-contact effect among the less intensive mobile phone users.

We can observe a similar effect also with respect to age (Table 10), where we found strong combined effects of non-coverage and non-response among the segment of persons with a fixed and mobile telephone in the $25-44$ age group.

Table 10: Age structure of mobile phone users according to their availability by fixed telephones in the RIS mobile phone survey 2003 and in the Labour Force Survey 2003.

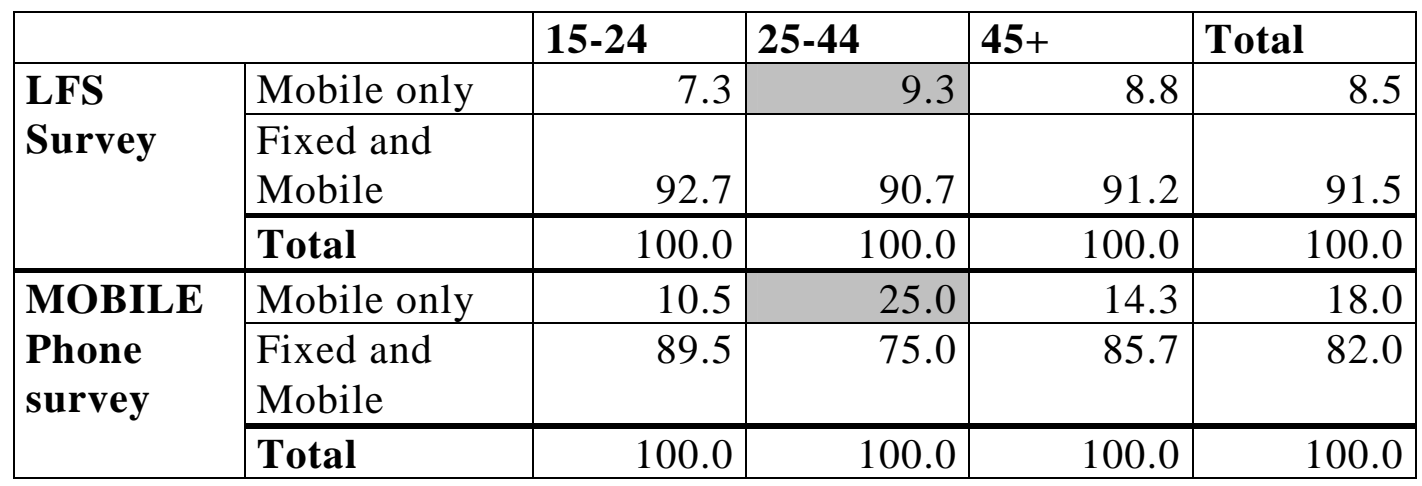


Consequently, we can expect that the mobile phone survey may possibly produce biases in the estimates also for some target variables, when these variables differ across the same segments. We can confirm this with the example of the unemployment rate, as the majority of segments that are over-represented in the mobile phone survey show higher unemployment rates.

\subsubsection{Segmentation of mobile phone users}

Let us further examine some behavioral and attitudinal characteristics of respondents in mobile phone surveys. We can observe that $84 \%$ of all respondents use the silent mode (Table 11) and that the majority (59\%) of respondents agree (or strongly agree) that they "feel lost and isolated without a mobile phone" (Table 12). Similarly, one third (35\%) agrees with the statement that they found certain enjoyment using their mobile phone, while almost one tenth (9\%) agrees that they do care about the opinion of other people as regards their mobile phone.

Table 11: Mobile phone use characteristics - RIS mobile phone survey 2003; $\mathrm{n}=103$.

\begin{tabular}{|l|c|}
\hline Characteristics & YES (\%) \\
\hline Use silent mode & 84 \\
\hline No fixed phone in the household & 18 \\
\hline Have more than one mobile number & 13 \\
\hline Use WAP or GPRS & 92 \\
\hline Know how to handle SMS & 48 \\
\hline Use call forwarding (paid) & \\
\hline
\end{tabular}

A typical mobile phone user in Slovenia thus makes some 5-10 calls per day and has the device usually on person. He uses the silent mode and SMS messages and is rather pragmatic (but not too pragmatic), perceiving the mobile phone as a communication tool. However, it seems that one third of the users also find it fun to use the mobile phone. In addition, roughly one tenth of mobile phone users cares somehow about the appearance of their mobile phones and may thus develop a specific relationship to their device.

Factor analysis (Table 13) reduced the above attitudes to three clear factors explaining almost $70 \%$ of the variance (first factor $27 \%$, second $22 \%$ and third $19 \%$ ). The first factor denotes the functional characteristics of mobile phone use. The second factor speaks about the intensity characteristic. The third component characterises the image characteristics of mobile phone use; these users place more attention on the design and other people's opinion about their device. 
Table 12: Means and relative frequencies (\%) for attitudes towards mobile phone use (RIS mobile phone survey 2003, $\mathrm{n}=103$ ).

\begin{tabular}{|l|r|r|r|r|r|r|r|}
\hline Statements & Mean & $\begin{array}{l}\text { 1 } \\
\text { strongly } \\
\text { disagree }\end{array}$ & $\begin{array}{l}\text { 2 } \\
\text { disagree }\end{array}$ & $\mathbf{3}$ & \multicolumn{1}{l|}{$\begin{array}{l}\text { agree } \\
\text { agre }\end{array}$} & $\begin{array}{l}\text { 5 } \\
\text { strongly } \\
\text { agree }\end{array}$ & Total \\
\hline $\begin{array}{l}\text { Mobile phone presents } \\
\text { merely a technical } \\
\text { device for calling }\end{array}$ & 4.28 & 2.9 & 5.8 & 5.8 & 31.1 & 54.4 & 100.0 \\
\hline $\begin{array}{l}\text { I enjoy using my } \\
\text { mobile phone }\end{array}$ & 2.63 & 29.1 & 18.4 & 19.4 & 26.2 & 6.8 & 100.0 \\
\hline $\begin{array}{l}\text { Without a mobile } \\
\text { phone I feel } \\
\text { disconnected from the } \\
\text { world }\end{array}$ & 3.33 & 24.3 & 10.7 & 5.8 & 26.2 & 33.0 & 100.0 \\
\hline $\begin{array}{l}\text { I always carry my } \\
\text { mobile phone with me }\end{array}$ & 4.45 & 1.0 & 4.9 & 9.7 & 17.5 & 67.0 & 100.0 \\
\hline $\begin{array}{l}\text { The design of my } \\
\text { mobile phone means a } \\
\text { lot to me }\end{array}$ & 2.75 & 28.2 & 14.6 & 22.3 & 24.3 & 10.7 & 100.0 \\
\hline $\begin{array}{l}\text { It is important for me } \\
\text { how other people } \\
\text { perceive my mobile } \\
\text { phone }\end{array}$ & 1.62 & 64.6 & 18.2 & 8.1 & 9.1 & 0.0 & 100.0 \\
\hline
\end{tabular}

Table 13: Factor analysis - RIS mobile phone survey 2003, $n=103$.

\begin{tabular}{|l|c|l|l|}
\hline \multicolumn{1}{|c|}{ Statements } & $\begin{array}{l}\text { Functional } \\
\text { characteristic } \\
\text { - Factor 1 }\end{array}$ & $\begin{array}{l}\text { Intensity } \\
\text { characteristic } \\
\text { - Factor 2 }\end{array}$ & $\begin{array}{l}\text { Image } \\
\text { characteristic } \\
\text { - Factor 3 }\end{array}$ \\
\hline $\begin{array}{l}\text { The mobile phone presents merely a technical } \\
\text { calling device }\end{array}$ & 0.762 & & \\
\hline I enjoy using my mobile phone & -0.530 & & \\
\hline $\begin{array}{l}\text { Without a mobile phone I feel disconnected from } \\
\text { the world }\end{array}$ & & 0.828 & \\
\hline I always carry my mobile phone with me & & 0.447 & \\
\hline The design of my mobile phone means a lot to me & & & 0.617 \\
\hline It is important how other people value my phone & & & 0.364 \\
\hline
\end{tabular}

If we cluster the mobile phone users (K Means Cluster Analysis), we find the following three segments (Table 14):

- Intensive functional users - these users perceive the mobile phone very pragmatically. They find rather little enjoyment or fun in its usage. Similarly, they do not care much about the design and other people's judgements about the appearance of their mobile phone. 
- Intensive emotional users - these users are highly attached to their device. They care a lot about the design of their device. They also show the highest concern for other people's judgements.

- Less intensive users - they have weaker attitudes towards their mobile phone. They carry the device with them least often and they find least enjoyment in its usage.

Table 14: Cluster analysis - average scores for attitudinal variables on a 1-5 scale for the three clusters (RIS mobile phone survey 2003, $\mathrm{n}=103$ ).

\begin{tabular}{|l|r|r|r|r|}
\cline { 2 - 4 } \multicolumn{1}{l|}{} & $\begin{array}{l}\text { Intensive } \\
\text { functional } \\
\text { users }\end{array}$ & $\begin{array}{l}\text { Intensive } \\
\text { emotiona } \\
\text { l users }\end{array}$ & $\begin{array}{l}\text { Less } \\
\text { intensive } \\
\text { users }\end{array}$ & \\
\hline Estimated share of the group in the population $\rightarrow$ & $\mathbf{3 3 \%}$ & $\mathbf{3 3 \%}$ & $\mathbf{3 3 \%}$ & $\mathbf{1 0 0 \%}$ \\
\hline Statements & Group 1 & Group 2 & Group 3 & Total \\
\hline $\begin{array}{l}\text { The mobile phone presents merely a technical } \\
\text { calling device }\end{array}$ & 4.65 & 3.68 & 4.41 & 4.28 \\
\hline I enjoy using my mobile phone & 2.65 & 3.06 & 2.43 & 2.63 \\
\hline $\begin{array}{l}\text { Without a mobile phone I feel disconnected from } \\
\text { the world }\end{array}$ & 4.42 & 4.55 & 1.46 & 3.33 \\
\hline I always carry my mobile phone with me & 4.55 & 4.84 & 4.03 & 4.45 \\
\hline The design of my mobile phone means a lot to me & 1.52 & 3.87 & 2.62 & 2.75 \\
\hline It is important how other people value my phone & 1.65 & 1.71 & 1.51 & 1.62 \\
\hline
\end{tabular}

To summarise, we can say that the respondents show considerable variations in their attitudes towards mobile phone use. When applying mobile phones in a survey process we also need to understand the attitudes of the different segments. It is possible that the pattern of mobile phone use and corresponding attitudes affect the response behavior.

Specifically:

- less intensive users may show lower contact rates,

- intensive (functional and emotional) users may have higher refusal rates,

- emotional users may show certain specific measurement problems.

\section{Conclusion}

In the majority of developed countries mobile phone penetration is steadily on the increase. This trend is accompanied with a decreasing coverage of fixed telephones, which is already approaching 60\% in some countries. Mobile phone surveys will thus soon become a compulsory alternative for general population surveys, where we have to include segments that have abandoned fixed telephones. Most probably, mobile phone surveys will become a complementary survey mode and will not entirely replace fixed telephone surveys. 
With respect to mobile phone coverage Slovenia is a typical EU country. Subscription mobile phone penetration is almost $100 \%$ and the share of mobileonly households is approaching $10 \%$ in 2004. Slovenia thus served as a case study for the feasibility of mobile phone interview surveys.

In general, mobile phone surveys face numerous methodological problems, such as costs, non-response, non-coverage and frame problems. We confirmed that all these problems actually exist in Slovenia, and we illustrated them. The unemployment rate example showed that even a relatively small non-coverage due to mobile-only households produced a serious underestimation in the unemployment rate (relative bias of $5 \%$ ).

We also demonstrated that caution is necessary when mobile phone coverage rates are reported. The rates may differ dramatically; for Slovenia they vary from $62 \%$ (personal mobile phone penetration rate within the adult population) to $97 \%$ (subscription mobile phone penetration rate for the entire population).

The comparisons of respondents in the mobile phone survey with the Labour Force Data showed certain differences in mobile phone usage across different socio-demographic segments, particularly amongst the young, male and single person households. The differences are somewhat smaller than expected. This occurred partially because non-coverage and non-response effects often cancelled each other.

With respect to mobile phone usage, less intensive mobile phone users are much less likely to appear in mobile phone surveys. Similarly, a considerable discrepancy exists with respect to the percentage of mobile-only households across different segments, which can be attributed to the differences in response rates.

The pilot mobile phone survey faced a relatively small amount of operational obstacles. However, the response rates were lower than comparable fixed telephone surveys. Of course, due to the lack of experience with mobile phone surveys, the corresponding solicitation approach might not be optimal.

In order to truly understand the role of mobile phones in a survey process we should also be aware of the social aspects of mobile phone usage. In our case, the Slovenian pilot mobile phone survey pointed towards three user segments: less intensive users, intensive pragmatic users and intensive emotional users. While the first two segments can show problems in contacts and co-operation, we may have some unpredictable response specifics in the latter segment. Further research on this topic is needed.

In future, the mobile phone penetration rates are expected to additionally increase, which will most probably be accompanied by a decrease of fixed telephone coverage. Soon, mobile phone surveys will become a serious challenge to the survey industry. However, in exchange for improved coverage, this survey mode will introduce numerous new problems into the survey process. 


\section{References}

[1] Biemer, P. and Lyberg, L. (2003): Introduction to survey quality. New York: Wiley.

[2] European Mobile Communication. EMC 2003.

http://www.emc-database.com/

[3] Groves, R.M., Beimer, P.P., Lyberg, L.E., Massey, J.T., Nicholls II, W.L., and Waksberg, J. (2001): Telephone survey methodology. New York: Wiley.

[4] Katz, J.E. 2003): The Machines that Becomes Us. Transaction Pub.

[5] Kuusela, V. and Simpanen, M. (2002): Effects of Mobile Phones on Phone Survey Practices and Results. ICIS Conference, Copenhagen.

[6] Labour Force Survey (2003). SURS: Statistical office of Republic Slovenia. http://www.stat.si

[7] Mobile Communications. Informa Telecoms Group (1996-2003).

[8] Rheingold, H. (2002): Mobile Virtual Communities. Receiver: Vodafone Group.

[9] RIS (2004): Research on Internet in Slovenia. On-line news 2004 at http://ris.org.

[10] SIBIS (2003): SIBIS Benchmarking Highlights. http://www.sibis-eu.org.

[11] Vehovar, V., Batagelj, Z., Lozar-Manfreda, K., and Zaletel, M. (2002): Nonresponse in web surveys. In R.M. Groves, D. Dillman, J.L. Eltinge, and R.J.A. Little (Eds): Survey nonresponse. New York, 229-242.

[12] Vehovar, V., Callegaro, M., and Kuusela, V. (2004a): Mobile phones as a survey tool. WAPOR Annual Conference 2004, May 11-13, 2004, Phoenix, US.

[13] Vehovar, V., Lozar-Manfreda, K., Dolničar, V., and Koren, G. (2004b): Mobile Phones as a Threat to the Survey Industry: A Typical Example from Europe. AAPOR $57^{\text {th }}$ Annual Conference. 